PACS CODES: 34.50RК, 31.70НQ, 95.55SН ; УДК 535.42.,539.184.

\title{
SENSING THE FINITE SIZE NUCLEAR EFFECT IN CALCULATION OF THE AUGER SPECTRA FOR ATOMS AND SOLIDS
}

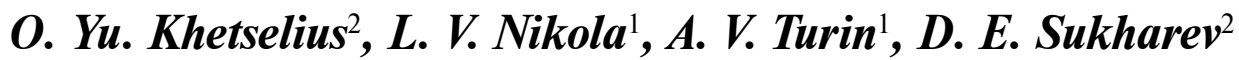 \\ ${ }^{1}$ I. I. Mechnikov Odessa National University, Odessa, Ukraine \\ ${ }^{2}$ Odessa National Polytechnical University, Odessa, Ukraine
}

\begin{abstract}
SENSING THE FINITE SIZE NUCLEAR EFFECT IN CALCULATION OF THE AUGER SPECTRA FOR ATOMS AND SOLIDS

O. Yu. Khetselius, L. V. Nikola, A. V. Turin, D. E. Sukharev
\end{abstract}

It is carried out the sensing finite size nuclear effect in calculations of the Auger spectra of solids. The energies of Auger electron transitions in ( $\mathrm{Ge}, \mathrm{Ag}, \mathrm{Au}, \mathrm{Fr})$ are calculated.

Key words: sensing, finite size nuclear effect, Auger spectrum, solids Резюме

ДЕТЕКТУВАННЯ ЕФЕКТУ СКІНЧЕННОГО РОЗМІРУ ЯДРА
У РОЗРАХУНКУ ОЖЕ СПЕКТРІВ АТОМІВ ТА ТВЕРДИХ ТІЛ

О. Ю. Хецеліус, Л. В. Нікола, О. В. Тюрін, Д. Е. Сухарев

Виконано оцінку внеску ефекту скінченного розміру ядра в енергії Оже спектра твердих тіл. Розраховані енергії Оже переходів у $\mathrm{Ge}, \mathrm{Ag}, \mathrm{Au}, \mathrm{Fr}$.

Ключові слова: ефект скінченного розміру ядра, Оже спектр, тверде тіло

Резюме

\section{ДЕТЕКТИРОВАНИЕ ЭФФЕКТА КОНЕЧНОГО РАЗМЕРА ЯДРА В РАСЧЕТЕ ОЖЕ СПЕКТРОВ АТОМОВ И ТВЕРДЫХ ТЕЛ}

\section{О. Ю. Хецелиус, Л. В. Никола, А. В. Тюрин, Д. Е. Сухарев}

Выполнена оценка вклада эффекта конечного размера ядра в энергии Оже спектра твердых тел. Рассчитаны энергии Оже переходов в $\mathrm{Ge}, \mathrm{Ag}, \mathrm{Au}, \mathrm{Fr}$.

Ключевые слова: эффект конечного размера ядра, Оже спектр, твердое тело

This paper is devoted to the sensing and estimating the finite size nuclear and radiative effects in calculations of the Auger spectra of solids. As introduction let us [7-9] note that the Auger electron spectroscopy remains an effective method to study the chemical composition of solid surfaces and near-surface layers [1-8]. Sensing the Auger spectra in atomic systems and solids gives the important data for the whole number of scientific and technological applications. So called two-step model is used most widely when calculating the Auger decay characteristics [1-3]. Since the vacancy lifetime in an inner atomic shell is rather long (about $10^{-17}$ to $10^{-14} \mathrm{~s}$ ), the atom ionization and the Auger emission are considered to be two independent processes. In the more correct dynamic theory of the Auger effect [3,7-9] the processes are not believed to be independent from one another. The fact is taken into account that the relaxation processes due to Coulomb interaction between electrons and resulting in the electron distribution in the vacancy field have no time to be over prior to the transition. In fact, a 
consistent Auger decay theory has to take into account correctly a number of correlation effects, including the energy dependence of the vacancy mass operator, the continuum pressure, spreading of the initial state over a set of configurations etc. in last years it has been shown that besides the interelectron correlation it is of a great importance the correct accounting for the relativistic, radiation and nuclear finite size effects contributions especilally under consideration of the atoms, molecules, solids of heavy and super heavy elements (eg.[10-14]). This problem is partly solved in this paper. As basic approach to calculating the Auger spectra of solids we use a new approach [7-9], basing on the S-matrix formalism by Gell-Mann and Low and QED perturbation theory (PT) formalism [10-13]. Earlier the method has been applied to calculate the ionization cross-sections of inner shells in various atoms, quasimolecules, solids [8,9].

Within the frame of QED PT approach the Auger transition probability and the Auger line intensity are defined by the square of an electron interaction matrix element having the form:

$$
\begin{gathered}
V_{1234}^{\omega}=\left[\left(j_{1}\right)\left(j_{2}\right)\left(j_{3}\right)\left(j_{4}\right)\right]^{1 / 2} \times \\
\times \sum_{\lambda \mu}(-1)^{\mu}\left(\begin{array}{cc}
j_{1} j_{3} & \lambda \\
m_{1}-m_{3} & \mu
\end{array}\right) \times \operatorname{Re} Q_{\lambda}(1234) ; \\
Q_{\lambda}=Q_{\lambda}^{\mathrm{Qul}}+Q_{\lambda}^{\mathrm{Br}} .
\end{gathered}
$$

The terms $Q_{\lambda}^{\mathrm{Qul}}$ and $Q_{\lambda}^{\mathrm{Br}}$ correspond to subdivision of the potential into Coulomb part $\cos |\omega| r_{12} / r_{12}$ and Breat one, $\cos |\omega| r_{12} \alpha_{1} \alpha_{2} / r_{12}$. The real part of the electron interaction matrix element is determined using expansion in terms of Bessel functions: :

$$
\begin{gathered}
\frac{\cos |\omega| r_{12}}{r_{12}}=\frac{\pi}{2 \sqrt{r_{1} r_{2}}} \times \\
\times \sum_{\lambda=0}(\lambda) J_{\lambda+1 / 2}\left(\omega \mid r_{<}\right) J_{-\lambda-1 / 2}\left(|\omega| r_{>}\right) P_{\lambda}\left(\cos \mathbf{r}_{1} \mathbf{r}_{2}\right) .
\end{gathered}
$$

where $J$ is the $1^{\text {st }}$ order Bessel function, $(\lambda)=2 \lambda+1$. The Coulomb part $Q_{\lambda}^{\text {Qul }}$ is expressed in terms of radial integrals $R_{\lambda}$, angular coefficients $S_{\lambda}$ [9]:

$$
\begin{gathered}
\operatorname{Re} Q_{\lambda}^{\text {Qul }}=\frac{1}{Z} \operatorname{Re}\left\{R_{l}(1243) S_{\lambda}(1243)+\right. \\
+R_{\lambda}(\tilde{1} 24 \tilde{3}) S_{\lambda}(\tilde{1} 24 \tilde{3})+ \\
\left.+R_{\lambda}(1 \tilde{2} \tilde{4} 3) S_{\lambda}(1 \tilde{2} \tilde{4} 3)+R_{\lambda}(\tilde{1} \tilde{2} \tilde{4} \tilde{3}) S_{\lambda}(\tilde{1} \tilde{2} \tilde{4} \tilde{3})\right\}
\end{gathered}
$$

As a result, the Auger decay probability is expressed in terms of $\operatorname{Re} Q_{\lambda}(1243)$ matrix elements:

$$
\begin{aligned}
\operatorname{Re} & R_{\lambda}(1243)=\iint d r_{1} r_{1}^{2} r_{2}^{2} f_{1}\left(r_{1}\right) f_{3}\left(r_{1}\right) \times \\
& \times f_{2}\left(r_{2}\right) f_{4}\left(r_{2}\right) Z_{\lambda}^{(1)}\left(r_{<}\right) Z_{\lambda}^{(1)}\left(r_{>}\right) .
\end{aligned}
$$

where $f$ is the large component of radial part of single electron state Dirac function; function $Z$ and angular coefficient are defined in refs. [7,8]. The other items in (3) include small components of the Dirac functions; the sign " $\sim$ " means that in (3) the large radial component $f_{i}$ is to be changed by the small $g_{i}$ one and the moment $l_{i}$ is to be changed by $\tilde{l}_{i}=l_{i}-1$ for Dirac number $ж_{1}>0$ and $l_{i}+1$ for $ж_{i}<0$. The Breat interaction is known to change considerably the Auger decay dynamics in some cases. The Breat part of $Q$ is defined in [7]-9]. The Auger width is obtained from the adiabatic Gell-Mann and Low formula for the energy shift [7]. The contribution of the $\mathrm{A}_{\mathrm{d}}=$ width with a vacancy $n_{\alpha} l j_{\alpha} m_{\alpha}$ is [7-9]:

$$
\sum_{\lambda} \frac{2}{(\lambda)\left(j_{\alpha}\right)} \sum_{\beta \gamma \leq f} \sum_{k>f} Q_{\lambda}(\alpha k \gamma \beta) Q_{\lambda}(\beta \gamma k \alpha),
$$

while contribution of the $\mathrm{A}_{\mathrm{ex}}=$ is [7-9]:

$$
\begin{aligned}
\frac{2}{\left(j_{\alpha}\right)} \sum_{\lambda_{1} \lambda_{2}} \sum_{\beta \gamma \leq f} \sum_{k>f} Q_{\lambda_{1}}(\alpha k \gamma \beta) Q_{\lambda_{2}}(\beta \gamma k \alpha) \times & \\
& \times\left\{\begin{array}{lll}
j_{\alpha} & j_{\gamma} & \lambda_{2} \\
j_{k} & j_{\beta} & \lambda_{1}
\end{array}\right\} .
\end{aligned}
$$

The partial items of the $\sum_{\beta \gamma} \sum_{k}$ sum answer to contributions of $\alpha^{-1} \rightarrow(\beta \gamma)^{-1} K$ channels resulting in formation of two new vacancies $\beta \gamma$ and one free electron $k: \omega_{k}=\omega_{\alpha}+\omega_{\beta}-\omega_{\alpha}$. The final expression for the width in the representation of $\mathrm{jj}$-coupling scheme of single-electron moments has the form:

$$
\Gamma\left(2 j_{1}^{o} l_{1}^{o}, 2 j_{2}^{o} l_{2}^{o} ; J\right)=\left.2 \sum_{j_{k} l_{k}} \Gamma\left(2 j_{1}^{o} l_{1}^{o}, 2 j_{2}^{o} l_{2}^{o} ; 1 l_{o}, k j l\right)\right|^{2}
$$

Here the summation is made over all possible decay channels. The basis of electron state functions was defined by the solution of Dirac equation (integrated numerically using the Runge-Cutt method) [10]. To account for the finite size of a nucleus we introduced the corresponding electric potential with the nuclear charge distribution in the Gaussian form [11] to the Dirac equation: 


$$
\rho(r \mid R)=\left(4 \gamma^{3 / 2} / \sqrt{\pi}\right) \exp \left(-\gamma r^{2}\right)
$$

Here $\gamma=4 / \pi R^{2} ; R$ is an effective nucleus radius, for which the standard Z-dependence is accepted [11]. The contribution of the lower order QED PT (radiative) corrections to the energies of the auger transitions is carried out according to the methodology $[11,12,14]$. The calculation of radial integrals $\operatorname{Re} R_{\lambda}(1243)$ is reduced to the solution of a system of differential equations [13]:

$$
\begin{gathered}
y_{1}^{\prime}=f_{1} f_{3} Z_{\lambda}^{(1)}(\alpha|\omega| r) r^{2+\lambda} \\
y_{2}^{\prime}=f_{2} f_{4} Z_{\lambda}^{(1)}(\alpha|\omega| r) r^{2+\lambda} \\
y_{3}^{\prime}=\left[y_{1} f_{2} f_{4}+y_{2} f_{1} f_{3}\right] Z_{\lambda}^{(2)}(\alpha|\omega| r) r^{1-\lambda}
\end{gathered}
$$

In addition, $y_{3}(\infty)=\operatorname{Re} R_{\lambda}(1243), y_{1}(\infty)=X_{\lambda}(13)$. The formulas for the Auger decay probability include the radial integrals $R_{\alpha}(\alpha k \gamma \beta)$, where one of the functions describes electron in the continuum state. The energy of an electron formed due to a transition $j k l$ is defined by the difference between energies of atom with a hole at $j$ level and doubleionized atom at $\mathrm{kl}$ levels in final state:

$$
E_{A}\left(j k l,{ }^{2 S+1} L_{J}\right)=E_{A}^{+}(j)-E_{A}^{2+}\left(k l,{ }^{2 S+1} L_{J}\right)
$$

To single out the above-mentioned correlation effects, the equation (12) can be presented as:

$$
\begin{gathered}
E_{A}\left(j k l,{ }^{2 S+1} L_{J}\right)= \\
=E(j)-E(k)-E(l)-\Delta\left(k, l ;{ }^{2 S+1} L_{J}\right)
\end{gathered}
$$

where the item $\Delta$ takes into account the dynamic correlation effects (relaxation due to hole screening with electrons etc.) To take these effects into account, the set of procedures elaborated in the atomic theory $[2,3]$ is used. For solid phase, the more precise form of equation (11) is [9]:

$$
\begin{gathered}
E_{A}^{s}\left(j k l,{ }^{2 S+1} L_{J}\right)= \\
=E_{A}\left(j k l,{ }^{2 S+1} L_{J}\right)+\Delta E^{s}+R_{\text {rel }}+e \Phi
\end{gathered}
$$

where $\Delta E^{s}$ is a correction for the binding energy change in the solid; $R_{\text {rel }}$, the same for out-of-atom relaxation; $e \Phi$ takes into account the work of output..

In table 1 we present the data on Auger electron energy for some solids calculated using the gaugeinvariant QED PT method with accounting for the QED and nuclear finite size effects (our work; column D), the semi-empirical method under Larkins' equivalent core approximation [2] (column A), the non-gauge-invariant relativistic PT [8], the gaugeinvariant relativistic PT [9] as well as experimental data [2].

Experimental and theoretical data for Auger electron energy: E - experiment;

Table 1

A, semi-empirical method - [2]; B- [8]; C - [15]; D- present paper;

\begin{tabular}{|c|c|c|c|c|c|c|}
\hline Solid & Auger line & E & Theory: A & Theory: B & Theory: C & Theory: D \\
\hline$G e$ & $L_{3} M_{4,5} M_{4,5}{ }^{I} G_{4}$ & 1146,2 & 1147,2 & 1146,6 & 1146,2 & 1146,2 \\
\hline$A g$ & $M_{5} N_{4,5} N_{4,5}{ }^{I} G_{4}$ & 353,4 & 358,8 & 354,1 & 353,5 & 353,4 \\
\hline
\end{tabular}

The calculation accuracy using the Larkins' method is within about $2 \mathrm{eV}$ as an average. The QED PT approach provides more accurate results that is due to a considerable extent to more correct accounting for complex electron interaction as well as the QED effects. The data in the columns $\mathrm{C}$ and $\mathrm{D}$ are more correct in comparison with data in the column B because of the more correct gauge-invariant procedure of generating the relativistic orbital basises. It is well known that for heavy systems, an account of these effects becomes very important in the quantitative relation and besides it is taken place very complicated compensation of the different QED radiative and nuclear (self-energy contribution, Lamb shift, nuclear finite size effect etc.) contributions. In this light it is interesting to consider the values of the nuclear finite size (nfz) contribu- tions to the corresponding Auger electron energies for $\mathrm{Ge}(Z=32)$ and $\mathrm{Ag}(Z=47): \mathrm{dE}_{\mathrm{nfz}}(\mathrm{Ge})=0,03$ $\mathrm{eV}$ and $\mathrm{dE}_{\mathrm{nfz}}(\mathrm{Ag})=0,35 \mathrm{eV}$. For comparison let us also present our estimates for more heavy elements (the Auger line $\left.M_{5} N_{4,5} N_{4,5}{ }^{1} G_{4}\right): \mathrm{Au}(\mathrm{Z}=79)$ and $\mathrm{Fr}$ $(\mathrm{Z}=87): \mathrm{dE}_{\mathrm{nfz}}(\mathrm{Au})=8,05 \mathrm{eV}$ and $\mathrm{dE}_{\mathrm{nfz}}(\mathrm{Fr})=27,92 \mathrm{eV}$. One can see that the account of the nuclear finite size effect becomes principally important for heavy elements.

\section{References}

1. Kulekshov V.F., Kukharenko Yu.A., Fridrikhov S.A. et al. Spectroscopy and Electron Diffraction in Solid Surfaces Studies. Nauka: Moscow, 1985.

2. Aberg T., Hewat G. Theory of Auger effect. SpringerVerlag: Berlin, 1979. 
3. Amusia M.Ya. Atomic photoeffect. Acad.Press: N. Y., 1988.

4. Letokhov V. Nonlinear Selective Photoprocesses in Atoms and Molecules. - Moscow, 1987.

5. Aglitsky E.V., Safronova U.I. Spectroscopy of Autoionization states of atomic systems. Energoatomizd.: Moscow, 1992.

6. Ivanova E.P., Ivanov L.N., Modern Trends in Spectroscopy of Multicharged Ions// Physics Rep. 1991. - Vol.166,N6. - P.315-390.

7. Glushkov A.V., Ivanova E.P., Ivanov L.N., Autoionization Phenomena in Atoms, Moscow State Univ., 1986.

8. Glushkov A.V., Ambrosov S.V., Prepelitsa G.P., Kozlovskaya V.P., Auger effect in atoms and solids: Calculation of characteristics of Auger decay in atoms, quasi-molecules and solids with apllication to surface composition analysis// Functional Materials. - 2003. - V.10, N2. - P.206-210.

9. Glushkov A.V., Ambrosov S.V., Nikola L.V., Sensing the Auger spectra for solids: new quantum approach// Sensor Electr.Micr.Tech. - 2006. - N3. - P.21-26

10. Glushkov A.V., Ivanov L.N. Radiation Decay of Atomic States: atomic residue and gauge non-in- variant contributions // Phys. Lett.A. - 1992. Vol.170,N1. - P.33-37

11. Glushkov A.V., Ambrosov S.V., Loboda A.V., Chernyakova Yu.G., .Svinarenko A.A., Khetselius O.Yu, QED calculation of the superheavy elements ions: energy levels, radiative corrections and hfs for different nuclear models// Nucl. Phys.A. - 2004. Vol. 734. - P.21-28.

12. Glushkov A.V., Ambrosov S.V., Loboda A.V., Gurnitskaya E.P., Khetselius O.Yu., QED calculation of heavy multicharged ions with account for correlation, radiative and nuclear effects// Recent Advances in Theor. Phys.\& Chem. Systems. - 2006. - Vol.15. P.285-300.

13. Glushkov A.V., Ambrosov S.V., Loboda A.V., Gurnitskaya E.P., Prepelitsa G.P., Consistent QED approach to calculation of electron-collision excitation crosssections and strengths: Ne-like ions // Int. Journ. Quant.Chem. - 2005. - Vol.104, N4. - P.562-570.

14. Prepelitsa G.P., Turin A.V., Chernyakova Yu.G., The features of emission spectra of the plasma in low inductive vacuum spark: Relativistic calculation with accounting for QED effects// Phys. Aerodisper. Syst. - 2003. - Vol.40. - P.327-332. 